\title{
Barriers to physical activity and socioeconomic position: implications for health promotion
}

\author{
David J Chinn, Martin White, Jane Harland, Christopher Drinkwater, Simon Raybould
}

In the United Kingdom, levels of physical activity in the general population are low $^{1}$ and there is great potential for improving public health by promoting physical activity. ${ }^{2}$ To achieve this health professionals need to have a good understanding of the principal barriers that operate and, in a UK study of people aged 16-74 years these included lack of time or recreational facilities, poor motivation, and ill health. ${ }^{1}$ Barriers vary by age ${ }^{13}$ and social class ${ }^{3}$ but knowledge of variation with other measures of socioeconomic position is scarce. We studied the relation between perceived barriers to physical activity, socioeconomic position, and other social characteristics in men and women aged 16-74 years.

\section{Methods}

Data for this study come from the Newcastle Health and Lifestyle Survey, ${ }^{4}$ which was a postal survey of a 1 in 30 sample, stratified by age and sex, of 6448 adults aged 16-74 years identified from the Family Health Services Authority register. Between October 1991 and March 1992 a self completion questionnaire was used to collect data on health related behaviours, socioeconomic position, health status, and knowledge and attitudes to health issues. With respect to physical activity respondents were asked if they did enough exercise for someone of their age and those who answered "no" were asked to identify perceived barriers from a list of eight commonly reported

Table 1 Barriers to physical activity by age, sex, education, marital status, housing tenure, working status, social class, car ownership and household income

Centre for Health and

Medical Research,

University of Teesside

D J Chinn

Department of
Epidemiology and
Public Health
D J Chinn
M White
J Harland

Department of

Primary Care

J Harland

C Drinkwater

Centre for Urban and Regional Development Studies

S Raybould

University of

Newcastle upon Tyne

Correspondence to: Dr Chinn, Centre for Health and Medical Research, University of Teesside, Middlesbrough, Cleveland, TS1 3BA.

Accepted for publication 6 October 1998

\begin{tabular}{|c|c|c|c|c|c|c|}
\hline & \multirow[b]{2}{*}{ Number } & \multicolumn{5}{|c|}{ Percentage citing each barrier } \\
\hline & & $\begin{array}{l}\text { Lack of } \\
\text { motivation }\end{array}$ & $\begin{array}{l}\text { Lack of leisure } \\
\text { time }\end{array}$ & $\begin{array}{l}\text { Lack of } \\
\text { money }\end{array}$ & $\begin{array}{l}\text { Lack of } \\
\text { transport }\end{array}$ & $\begin{array}{l}\text { Illness/ } \\
\text { disability }\end{array}$ \\
\hline \multicolumn{7}{|l|}{ Age group } \\
\hline $16-24$ & 420 & 48.2 & 57.7 & 49.0 & 14.3 & 4.4 \\
\hline $25-34$ & 607 & 48.5 & 63.1 & 35.2 & 9.9 & 5.5 \\
\hline $35-44$ & 529 & 49.5 & 58.3 & 20.3 & 6.1 & 12.3 \\
\hline $45-54$ & 354 & 49.9 & 44.8 & 21.2 & 6.5 & 19.5 \\
\hline $55-64$ & 300 & 43.8 & 24.1 & 21.6 & 6.9 & 33.0 \\
\hline $65-74$ & 164 & 33.5 & 5.6 & 15.5 & 9.3 & 51.9 \\
\hline $\mathrm{p}$ value $\mathrm{e}^{\star \star}$ & & 0.010 & $<0.0001$ & $<0.0001$ & 0.0008 & $<0.0001$ \\
\hline \multicolumn{7}{|l|}{$\mathrm{Sex}^{\star}$} \\
\hline Men & 1070 & 46.3 & 47.0 & 26.8 & 7.4 & 14.6 \\
\hline Women & 1305 & 47.9 & 49.9 & 28.5 & 9.6 & 10.0 \\
\hline $\mathrm{p}$ value & & 0.41 & 0.19 & 0.38 & 0.061 & 0.001 \\
\hline \multicolumn{7}{|l|}{ Education ${ }^{\star}$} \\
\hline Elementary & 1446 & 45.3 & 46.7 & 30.1 & 8.3 & 12.9 \\
\hline Further education/university & 750 & 53.7 & 55.3 & 20.8 & 8.1 & 9.6 \\
\hline $\mathrm{p}$ value & & 0.0003 & 0.0003 & $<0.0001$ & 0.86 & 0.029 \\
\hline \multicolumn{7}{|l|}{ Marital status ${ }^{\star}$} \\
\hline Married or living with a partner & 1472 & 48.3 & 55.5 & 23.8 & 6.9 & 10.4 \\
\hline Single, widowed or divorced & 892 & 48.2 & 35.9 & 34.9 & 11.6 & 15.6 \\
\hline $\mathrm{p}$ value & & 0.44 & $<0.0001$ & $<0.0001$ & 0.0002 & 0.0004 \\
\hline \multicolumn{7}{|l|}{ Tenure ${ }^{\star}$} \\
\hline Owner occupier & 1455 & 50.2 & 58.1 & 18.7 & 6.8 & 8.3 \\
\hline Council tenant & 894 & 42.2 & 33.0 & 43.1 & 11.4 & 18.7 \\
\hline $\mathrm{p}$ value & & 0.0002 & $<0.0001$ & $<0.0001$ & 0.0001 & $<0.0001$ \\
\hline \multicolumn{7}{|l|}{ Employment status $\dagger^{\star}$} \\
\hline Employed & 1426 & 51.6 & 64.2 & 18.5 & 5.8 & 4.9 \\
\hline Unemployed & 169 & 51.8 & 12.3 & 57.4 & 11.8 & 10.0 \\
\hline $\mathrm{p}$ value & & 0.95 & $<0.0001$ & $<0.0001$ & 0.0018 & 0.011 \\
\hline \multicolumn{7}{|l|}{ Social class (household) * } \\
\hline Non-manual & 1047 & 53.6 & 55.9 & 19.3 & 6.9 & 9.1 \\
\hline Manual & 1099 & 43.7 & 45.6 & 33.8 & 9.4 & 12.8 \\
\hline $\mathrm{p}$ value & & $<0.0001$ & $<0.0001$ & $<0.0001$ & 0.031 & 0.005 \\
\hline \multicolumn{7}{|l|}{ Car ownership^ } \\
\hline Yes & 1554 & 50.3 & 56.6 & 19.4 & 4.7 & 8.2 \\
\hline No & 770 & 42.1 & 33.4 & 43.6 & 16.0 & 20.4 \\
\hline $\mathrm{p}$ value & & 0.0002 & $<0.0001$ & $<0.0001$ & $<0.0001$ & $<0.0001$ \\
\hline \multicolumn{7}{|l|}{ Annual household income $(£)^{\star}$} \\
\hline$<5000$ & 494 & 37.9 & 22.4 & 57.0 & 17.4 & 24.6 \\
\hline $5-10000$ & 573 & 46.8 & 41.3 & 35.1 & 11.7 & 13.6 \\
\hline $10-15000$ & 433 & 50.3 & 61.2 & 19.7 & 6.2 & 7.3 \\
\hline$>15000$ & 718 & 53.2 & 64.6 & 10.0 & 2.3 & 5.8 \\
\hline $\mathrm{p}$ value ${ }^{\star \star}$ & & $<0.0001$ & $<0.0001$ & $<0.0001$ & $<0.0001$ & $<0.0001$ \\
\hline
\end{tabular}

* Predicted at age 40 (logistic regression).

$\star \star$ Mantel-Haenszel test for trend.

† For those economically active. 
ones. ${ }^{1}$ Measures of socioeconomic position included housing tenure, education, car ownership, and household take home pay (income) in one of 12 categories that, subsequently, was classified into one of four quartile categories $(<£ 5000, £ 5000-9999, £ 10000-14999$, $\geqslant £ 15000$ per annum). Linear trends were assessed using the Mantel-Haenszel test and comparisons of proportions were made using logistic regression with adjustment for age, which was included as a covariate (SPSSx).

\section{Results}

After adjusting for exclusions and unforeseen losses in the sample, replies were received from 4140 persons ( 1927 men and 2213 women), a response rate of $69 \%$. Forty three per cent of men and $39 \%$ of women considered they did enough exercise for someone of their age. Among 1070 men and 1305 women who did not feel they did enough exercise principal barriers to exercise were lack of leisure time ( $47 \%$ of men and $51 \%$ of women) and lack of motivation ( $46 \%$ of men and $48 \%$ of women). However, barriers varied by age, social class, marital status, and measures of socioeconomic position (table 1). For example, lack of motivation and lack of time were related positively to income while illness or disability, lack of money, and lack of transport were related negatively to income.

\section{Discussion}

The relation between health and socioeconomic position is complex and, as yet, not fully understood. Levels of leisure time physical activity are patterned socioeconomically ${ }^{14}$ and our data suggest possible reasons. Principal barriers to increased activity vary by age group ${ }^{1}$ and social class based on occupation ${ }^{3}$ and these trends were confirmed in this study. However, our data suggest they are also influenced by other measures of socioeconomic position. For example, lack of money and lack of access to transport are more likely to be cited by the less affluent. These findings have relevance for health promotion programmes targeted at indivduals as research suggests that people who cite only "external" barriers such as lack of money and access to transport are more likely to change exercise behaviour than people who cite "internal" barriers such as lack of motivation and time. ${ }^{5}$ Thus, interventions to promote physical activity in poorer populations may require different strategies from those targeted at more affluent groups. These may entail the use of incentives or subsidies, or alternative motivational strategies that increase access to marginal resources. These findings have important implications for the development of exercise prescription or referral schemes and physical activity policies at organisational and community levels.

We are grateful to the people of Newcastle upon Tyne who completed the questionnaires and to the many individuals who completed the questionnaires and to the many individuals who
helped at various stages of the study; they are identified and helped at various stages of the study; they are identifir contribution acknowledged in the report cited. ${ }^{4}$
their

Funding: the NHLS was funded by Newcastle Health Authority. Dr David Chinn and Ms Jane Harland were supported by a grant from the NHS R\&D Cardiovascular Disease and Stroke Prant from the

Conflicts of interest: none

1 Sports Council and Health Education Authority. The AlliedDunbar National Fitness Survey - Main findings. London:

2 Health Education Authority. Health Update 5: Physical activity. London: HEA, 1995

3 Health Education Authority. Health in England 1996. What people know, what people think, what people do. London: Office of National Statistics, 1997.

4 Harrington B, White M, Foy C, et al. The Newcastle Health and Lifestyle Survey, 1991. Newcastle upon Tyne: Newcaste Health Authority and Department of Epidemiology and Public Health, University of Newcastle upon Tyne, 1993.

5 Ziebland S, Thorogood M, Yudkin P, et al. Lack of willpower or lack of wherewithal? "Internal" and "external" barriers to changing diet and exercise in a three year follow-up of 1998;46:461-5. 